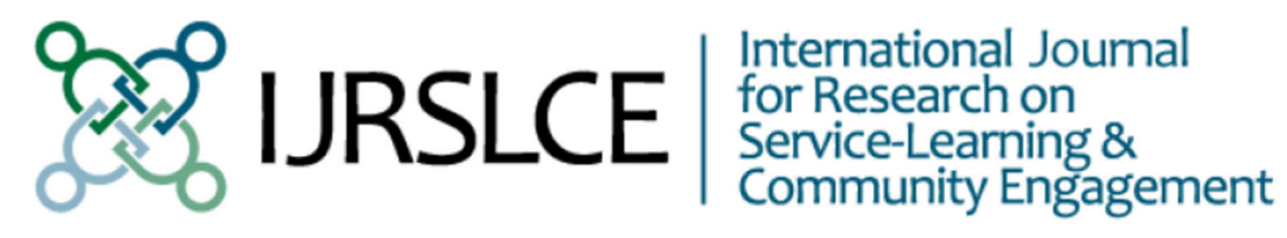

Volume 3 | Issue 1

Article 16

2015

Student Outcomes, K-20

\author{
Lane Perry \\ Billy O'Steen
}

This article was originally published at:

https://journals.sfu.ca/iarslce/index.php/journal/article/view/160/84

Recommended Citation

Perry, L., \& O'Steen, B. (2015). Student Outcomes, K-20. International Journal of Research on Service-Learning and Community Engagement, 3(1), Article 16. 


\title{
Student Outcomes, K-20
}

\author{
Lane Perry \\ Western Carolina University \\ Billy O'Steen \\ University of Canterbury
}

\section{Section Co-Editors}

While outcomes that lead to positive impacts in the community, within the institution, and for faculty are important to identify, the cornerstone of the service-learning and community engagement movement is the impact that these pedagogical approaches have on the student. Service-learning is an inquiry-oriented approach to teaching and learning in which students use academic knowledge and skills to address a real public problem. Myriad studies have demonstrated that well-designed and -implemented service-learning and community engagement experiences can promote the learning and transfer of meaningful subject area, civic, personal, career, and intercultural understandings and skills, as well as positive personal, civic, and moral development. However, while a body of well-established findings exists, questions remain. For example, theory-driven questions about outcomes, about the contribution of service-learning and community engagement in addition or in contrast to other active-learning methods, about the role of contextual variables, and about the effects of specific types of service-learning and community engagement remain.

The student outcomes section of this issue of IJRSLCE provides insight into either untapped outcomes or approaches that help learners reach empirically established outcomes. Each article is summarized briefly here:

- In "Students' Emotional Experiences in Direct vs. Indirect Academic Service-Learning Courses," Darby qualitatively explores the impetus, source, and impact of emotion associated with direct or indirect service-learning experiences. This investigation found that while the source for emotional impact differs according to whether direct or indirect engagement occurs, there is still an emotional aspect to students' experiences.

- In their research article "Using Active Learning Strategies to Increase Pre-Service Teachers' Efficacy in a Service-Learning Course," Nelson, Crow, and Tice focus primarily on the impact of a contextually developed active-learning strategy on pre-service teachers' efficacy. The active-learning sequence developed was beneficial to participating students and was a preferred method of instruction for engaging students with course content.

- In the research article "The Impacts of Undergraduate Service-Learning on Post-Graduation Employment Outcomes," Matthews, Dorfman, and Wu quantitatively explore employment outcomes of 44 unique matched pairs in which one member of each pair had experienced service-learning and one had not. For those students who engaged in service-learning experiences, paired t-tests found significantly higher starting salaries and significantly shorter times to receive a first raise. 
- Perry and Perry offer a similar topic in their research article "Final-Year Transition and Service-Learning: Working Together as a Vehicle for Student Engagement, Development, and Life Preparedness," though they frame their work more as a call for further research into life and career preparedness. This article synthesizes two recent studies that endeavored to find the common ground between the demands of the post-university/final-year transition and the experiences associated with service-learning pedagogy.

- Given the adjustment challenges facing college students, Nicotera, Brewers, and Veeh used a series of measures to explore the question of how civic activity in high school and early college contributes to well-being among first-year college students. Their findings suggest that engaging in civic activities during the first-year of college is positively associated with aspects of student well-being.

- In the theoretical/conceptual article "The Emerging 360 Degree Model for Global Citizenship Education," Breitkreuz and Songer identify the complexity and reality of globalization, the role of the engaged global citizen, and the imperative for graduates of U.S. higher education to become competent contributors to the global community. To address this complex reality, the authors offer the 360 Degree Model for Global Citizenship Education as a resource for engaging students and positively influencing student growth in global understandings and intercultural abilities within health-science and STEM-focused contexts.

- In the research article, "Meeting Students Where They Are: Introducing Service-Learning with Digital Media to Increase Self-Efficacy for Future Community Engagement," Peterson, Haringa, Malinski, Bishop, and Stein evaluate the efficacy of using digital media to introduce service-learning to undergraduate and graduate students. Results from the Community Service Self-Efficacy Scale and supplemental questions about student experiences indicated that those who viewed the digital media prior to service engagement had higher self-efficacy and a more positive experience than those who did not experience the contextualizing video introduction. 